\title{
Gestão, planejamento e avaliação de políticas de ciência e tecnologia: hora de rever?
}

\author{
Management, planning and assessment of science \\ and technology policies: time to review?
}

Marília Bernardes Marques 1

\begin{abstract}
This article addresses the issue of science and technology policies as well as its management and evaluation. Reviews the trajectory of science and technology during the last five decades of this century and analyses how science has progressively turned to the markets and to high-tech firms, simultaneously to the increase in the governmental intervention steered to integrate science and technology in the whole economy. It also analyses the notion of national innovation system and its relations with the science and technology policies. To conclude, the paper considers the problem of the limits and trends of the governmental action directed to science and technology in developing and underdeveloped countries.

Key words Science and Technology Policies; National Innovation System; Health Research; Technological Innovation; Social and Economic Development; Science and Technology Assessment; Sustainable Development
\end{abstract}

Resumo O presente artigo aborda o tema das políticas de ciência e tecnologia e as questões relativas à sua gestão, planejamento e avaliação. Revisa a trajetória da ciência e tecnologia nas cinco últimas décadas deste século, analisando como a ciência voltou-se progressivamente para os mercados e empresas de alta tecnologia, ao mesmo tempo em que cresceria a intervenção do Estado dirigida à integração da ciência e da tecnologia ao conjunto da economia. A seguir, analisa a noção de sistema nacional de inovação e suas relações com o tema das políticas de ciência e tecnologia. O texto finaliza retomando o problema dos limites e dos rumos da ação governamental sobre a ciência e a tecnologia nos países em desenvolvimento e subdesenvolvidos.

Palavras-chave Politicas de Ciência e Tecnologia; Sistema Nacional de Inovação; Pesquisa em Saúde; Inovação Tecnológica; Desenvolvimento Econômico e Social; Avaliação Social da Ciência e Tecnologia; Desenvolvimento Sustentável

\footnotetext{
${ }^{1}$ Centro de Informação Científica e Tecnológica, Fundação Oswaldo Cruz, Av. Brasil 4365, 21045-900 Rio de Janeiro, RJ, Brasil bmarques@dcc001.cict.fiocruz.br
} 


\section{Introdução}

Podemos afirmar, sem medo de errar, que a maior parte da literatura acadêmica relativa ao tema das políticas científicas e tecnológicas é produto das últimas três décadas, é internacional e, de modo quase que exclusivo, escrita por economistas, sociólogos, historiadores, filósofos e engenheiros. É fácil encontrar nesse universo textos abordando aspectos controvertidos e atuais, relativos à ciência e tecnologia (C\&T) gerada nas áreas da saúde humana e da medicina, indicando a relevância social e econômica crescente das mesmas. Para corroborar, basta dizer que o maior projeto envolvendo ciência, tecnologia e governo nos anos 90 é o Projeto do Genoma Humano, financiado pelos governos dos Estados Unidos e de outros países. Superando as expectativas suscitadas nos anos 40 pelo Projeto Manhattan da bomba atômica e, nos anos 60, pelo Projeto Apollo do homem na Lua, esse projeto do final dos anos 80 pretende codificar todos os genes humanos e promete um grande número de avanços médicos espetaculares (Cook-Deegan, 1994). De fato, os resultados alcançados até o presente confirmam que essa promessa está sendo cumprida, com a biologia e a medicina entrando na nova era da Ciência do Genoma Collins et al. (1998).

$\mathrm{O}$ interesse internacional demonstrado por diversos campos disciplinares para com a pesquisa em saúde e em medicina contrasta com a relativa escassez com que temas relacionados à política de $\mathrm{C} \& \mathrm{~T}$ e às questões relativas à sua gestão e avaliação são abordados na literatura dedicada aos problemas e políticas de saúde. No Brasil este quadro se repete, sendo escassa a literatura mais recente disponível no meio acadêmico (Novaes, 1996; Marques, 1998). Esta constatação, por si só, constitui um bom motivo para que o tema seja revisto.

Por outro lado, no Brasil, nas duas últimas décadas, observou-se um considerável declínio das atividades governamentais de planejamento econômico e social e das perspectivas de médio e longo prazo. No período atual assinalam-se as dificuldades para a retomada do desenvolvimento, em face da crescente instabilidade na economia mundial. Nesse período, as políticas de C\&T tornaram-se, cada vez mais, reféns da visão de curto prazo e mesmo a defesa da C\&T passou a significar, quase que exclusivamente, lutar pela preservação dos - ínfimos - recursos financeiros públicos destinados às atividades científicas.

$\mathrm{Na}$ contramão desse processo, muitas palavras foram ditas e vários textos foram escritos, no ano de 1994, em defesa de uma política nacional de CeT em saúde (Academia Brasileira de Ciências, 1994; Brasil, Ministério de Saúde, 1994). No entanto, o Ministério da Saúde, por razões não devidamente analisadas, permaneceu indiferente à proposta coletiva gerada naquele processo e no seio da própria comunidade da saúde coletiva emergiram vozes considerando-a uma natimorta, sem oferecer explicações para um tal desfecho. $\mathrm{O}$ fato de o setor saúde continuar sem uma política, explícita ou implícita, para C\&T evidencia a necessidade de reconsiderar aquela proposta. Afinal, quem está com a razão: os defensores de uma política nacional de CßT em saúde ou o Ministério da Saúde? Será o caso de se continuar defendendo políticas explícitas setoriais para C\&T ou uma única política nacional de C\&T de corte horizontal constitui a melhor opção? O desafio contemplado nesta questão é, portanto, outro bom motivo para que o tema comece a ser revisto coletivamente.

A dimensão nacional não pode, porém, ser analisada sem se levar em conta aspectos e tendências internacionais relevantes. No atual contexto internacional, sobretudo na Europa Ocidental, Japão e Estados Unidos, os imperativos econômicos e comerciais, sintetizados no termo competitividade, muito mais do que as motivações militares, têm conferido relevância prática e teórica ao tema das políticas de C\&T. No uso corrente, a palavra competitividade traduz a capacidade comercial de um país para subir no ranking dos mercados internacionais. Em geral, não é associado aos temas "qualidade de vida" e "ambiente".

As tendências observadas no cenário internacional evidenciam que, no presente, a fronteira da ciência está muito mais voltada para as necessidades dos mercados e empresas de alta tecnologia do que para os desafios sociais e ambientais. Nelas encontram-se as razões para o predomínio, nos países ricos e desenvolvidos, de uma interpretação bastante egoísta da C\&T: tendo a ciência se transformado no elemento essencial da própria potência, razão de sua bem sucedida capacidade de competir e de acumular riqueza, passou a constituir seu principal patrimônio e seu maior negócio. Na atualidade, a afirmação de que os resultados da ciência são patrimônio 
da humanidade, tornou-se, portanto, uma interpretação idealizada que, na maior parte das vezes, não encontra correspondência prática. Vem daí os constantes conflitos de interesses públicos e privados que cercam a apropriação dos resultados da C\&T, como nos processos de transferência de tecnologia e nas negociações comerciais internacionais, as quais ressaltam as divergentes visões nacionais a respeito da propriedade intelectual Marques (1993).

Com as transformações da economia mundial nas décadas de 70 e 80 e com os avanços nas tecnologias de informação e comunicação e na biotecnologia, aqueles países, certas regiões e grupos sociais tornam-se mais ricos e poderosos, paralelamente ao crescimento mundial da pobreza, ao agravamento da devastação ambiental, ao aumento da criminalidade e da violência urbana e às guerras étnicas Hobsbawm (1995). É amplamente reconhecido que nenhum dos problemas antes mencionados pode ser solucionado unicamente com mais e melhores resultados científicos e tecnológicos, apesar de estes desempenharem um papel importante. Apesar deste reconhecimento, a metáfora da competitividade tem alavancado a C\&T para uma posição de deus ex-machina ao mesmo tempo que dissemina uma - dejá $v u$ - fé na economia de mercado, como única via para superar os desequilíbrios mundiais.

A constatação de que, no plano internacional, as políticas de Estado têm sistematicamente falhado no que diz respeito a canalizar o desenvolvimento científico e tecnológico para a satisfação das necessidades sociais, não obstante sua capacidade de incrementar as vantagens comparativas no processo de competição econômica e comercial, sobretudo as das nações que dominam a fronteira da ciência, suscita a seguinte indagação: neste fin de siécle, estarão as políticas de Estado dedicadas à C\&T merecendo uma nova orientação?

O presente artigo tem o propósito - modesto - de oferecer uma contribuição inicial à tarefa complexa, tanto em termos acadêmicos quanto políticos, de rever criticamente o tema da gestão e avaliação das políticas de C\&T. Nosso objetivo aqui é trazer algumas questões de base que possam ser úteis a um processo amplo de revisão do tema gestão e avaliação das políticas de C\&T e de suas estratégias e prioridades.

\section{A trajetória recente da $\mathrm{C} \& \mathrm{~T}$ na economia e na política}

Em meio ao processo de afirmação da nova ordem econômica internacional, fundada na hegemonia americana Teixeira (1994), emergiu aquela que, entre as várias interpretações das relações ciência e sociedade, alcançou maior influência durante os anos imediatamente posteriores à II Guerra Mundial: a introduzida pelo conselheiro científico do Presidente Roosevelt, dos Estados Unidos, Vannevar Bush. Em seu célebre relatório publicado em 1945, The Endless Frontier: A Report to the President on a Program for Postwar Scientific Research, Bush sustentava que é o mercado quem determina os usos últimos - sociais e econômicos - da ciência MacLean et al. (1998).

A defesa da liberdade da ciência, isto é, da preservação da autonomia da ciência fundamental, da pesquisa básica, em relação às interferências externas de toda ordem, ocupava um lugar central. A intervenção do Estado nas atividades de ciência e tecnologia, entretanto, se tornaria amplamente aceita após o reconhecimento de que as demandas do mercado não são suficientes para estimular o desenvolvimento daquelas.

Favas contadas a favor e contra o peso da "mão invisível" de Adam Smith, o fato é que, tanto pelas razões estratégicas dominantes logo depois do fim da II Guerra Mundial quanto, posteriormente, em nome da competitividade, a ciência tornou-se alvo da política de Estado. As políticas nacionais de C\&T tenderam a tornar-se cada vez mais intervencionistas e explícitas no planejamento e na gerência das atividades científicas. A ciência foi adquirindo uma dependência cada vez maior do Estado, consumindo volumes crescentes de recursos públicos.

No bojo dessa irreversível transformação, o conhecimento científico desceria alguns degraus no pódio dos bens universais e, ganhando o mercado, passaria a ter o status de bem econômico, tornando-se uma mercadoria como tantas outras (Salomon, s.d.). Essa tendência observou-se sobretudo nos Estados Unidos e na Inglaterra, países onde a acentuada autonomia que as comunidades científicas tinham desfrutado, no pós-guerra, para definir as suas agendas de pesquisa básica, sofreria uma significativa erosão a partir do final dos anos 60. Generalizaram-se as cobranças para reavaliar as instituições acadêmicas, suas es- 
truturas organizacionais e os mecanismos e critérios internos de alocação de recursos para a pesquisa. Entre os políticos, gestores e administradores cresceria a convicção de que era preciso cortar o impulso dos cientistas para perseguir o conhecimento científico apenas pelo bem do próprio conhecimento científico e dirigi-los para projetos mais aplicados, sobretudo que gerassem resultados econômicos mais imediatos Dasgupta \& David (1994).

A partir do final do anos 60 e nos 70, em meio às dificuldades econômicas, ao choque do petróleo e ao crescimento das demandas sociais, sobretudo o agravamento do desemprego, as políticas específicas que no passado haviam conferido às questões científicas propriamente ditas uma quase exclusividade, passaram a conferir prioridade à tecnologia na alocação de recursos.

Nesse novo contexto, a expressão pesquisa e desenvolvimento, ou $P \& D$, tornou-se o modo comum de referir-se a todas as etapas que levam a uma dada inovação tecnológica, antes do uso final e pela primeira vez de um produto ou serviço ou antes da sua comercialização Papon \& Barré (1996). Desde então, certos círculos que sempre colocaram em dúvida a capacidade do Estado para administrar recursos escassos com eficiência, no caso da ciência passaram a defender a necessidade do governo formular políticas de alocação de recursos para a pesquisa básica e estimular o estabelecimento de vínculos estreitos entre o trabalho acadêmico e projetos de $\mathrm{P} \& \mathrm{D}$ orientados para o mercado.

Nos 80, afirmou-se o paradigma da nova biotecnologia, sobretudo nas grandes universidades dos Estados Unidos e generalizou-se o reconhecimento de que na pesquisa acadêmica está a chave para a obtenção de produtos de alto valor comercial. A indústria aumentou seus investimentos na pesquisa universitária e, ao mesmo tempo, proliferaram nas universidades os escritórios de patentes e de transferência de tecnologia, os parques de pesquisa, as incubadoras de negócios e os centros de pesquisa universidade-indústria. A política pública nos Estados Unidos assegurou a devida assistência a esses novos empreendimentos, sendo que de 1984 a 1990 a National Science Foundation chegou a fazer da competitividade econômica um componente integrante da sua missão Geiger (1997).

Foi um período em que também cresceu o reconhecimento de que a ciência deve prestar contas à sociedade. A noção de avaliação social da C\&T ganharia crescente relevância, sobretudo na Europa Ocidental, desdobrandose em metodologias destinadas a antecipar e prever as conseqüências negativas da incorporação e da difusão de uma determinada tecnologia. Em nome dessa prestação de contas, desenvolveram-se novos processos de avaliação e acompanhamento do impacto e do custo social da tecnologia, isto é, de suas repercussões nas taxas de emprego, nas condições de trabalho, no ambiente (tóxicos e resíduos químicos), na privacidade dos indivíduos (informação e informática), no patrimônio genético da humanidade, na probabilidade de grandes catástrofes associada aos megaprojetos tecnológicos (construção de centrais nucleares e de grandes barragens hidrelétricas).

Para Salomon (s.d., p. 97), a avaliação social da $\mathrm{C} \& \mathrm{~T}$ veio somar-se às funções regulatórias tradicionais do Estado: Esta função pode ser considerada como o esforço mais recente para aplicar os métodos científicos à gestão e à regulação da mudança tecnológica. De fato, em diversos países, a avaliação tecnológica tornou-se um processo socializado e democrático, compartilhado pelo parlamento e por órgãos de defesa do consumidor e difundido pela mídia. Mais do que simples exercício científico, de aplicação de um conjunto isolado de metodologias, atualmente, a noção de avaliação social da C\&T refere-se a processos políticos e sociais concretos em torno das questões de risk assessment, biossegurança e bioética, todas alavancadas no novo paradigma da biotecnologia de terceira geração.

Dessa forma, em nome do imperativo da prestação de contas à sociedade, houve um estímulo ao controle do Estado sobre a ciência, observado na proliferação de comissões nacionais para definir regras para temas específicos, na construção de bases de dados e no desenvolvimento de indicadores para medir a produção científica e para julgar, do ponto de vista da integridade ética, os resultados das pesquisas realizadas no ambiente universitário. Não obstante, a autonomia da ciência continuou sendo preservada porque, internacionalmente, as decisões e as escolhas, no interior de cada disciplina ou área acadêmica, continuaram sendo pautadas, de modo quase exclusivo, pelo critério do mérito científico, assentado no julgamento de pares.

Em alguns países, como Alemanha, Holanda, Reino Unido e Austrália, a tendência a ligar 
mais explicitamente a pesquisa científica às necessidades econômicas e à prestação de contas à sociedade viu-se refletida na disseminação da prática de traçar cenários para a pesquisa ou cenários tecnológicos (research foresight ou technology foresight) para melhor identificar futuras tecnologias ou áreas de pesquisa prioritárias, por meio da consideração e da combinação das perspectivas da science push (empurrão da ciência) e demand pull (puxada da demanda). Busca-se por meio de tais metodologias antecipatórias obter processos decisórios mais racionais, isto é, decisões políticas baseadas em regras operacionais bem pragmáticas, para orientar a escolha da tecnologia prioritária e a alocação orçamentária destinada à ciência básica, à ciência aplicada e às diferentes disciplinas ou áreas universitárias Godet (1994).

Sob a influência dessas novas noções que atualmente influenciam a interpretação predominante das relações entre ciência e sociedade, em toda parte e como jamais fora antes observado, o gasto público com a ciência passou a ser amplamente discutido, recomendando-se o estabelecimento de carteiras de pesquisas estratégicas, ou seja, experimentos capazes de gerar resultados promissores quanto ao alcance de certos desenvolvimentos sociais, econômicos e regionais.

Nesse processo, também os usuários da ciência, estivessem estes na indústria ou em outros setores, passaram a exigir um peso maior não só no controle social da ciência como na definição da agenda de pesquisas estratégicas do setor público e dos critérios para a repartição dos recursos públicos. Múltiplos interesses ganharam assento na mesa de negociações constituída em torno da atividade científica.

Não obstante, com o Estado voltando-se prioritariamente para a integração da C\&T ao conjunto da economia, entre os analistas da inovação tecnológica, a indagação central passaria a ser: qual é a eficácia e quais são os limites das políticas públicas para satisfazer o imperativo da inovação tecnológica? O alvo, porém, é a empresa. Assim, para o principal centro de referência, a Social Policy Research Unit-SPRU, da Universidade de Sussex, Reino Unido, algumas das perguntas a serem respondidas são: por que as empresas em alguns países e regiões mostram uma maior capacidade para assimilar e explorar novos conhecimentos e para inovar do que outras? O que o governo pode fazer para encorajar esse processo? Como estão mudando os sistemas nacionais de pesquisa pública à luz das novas demandas para a C\&T e para o desenvolvimento de certas habilidades profissionais? Como é transferida a tecnologia quando as empresas multinacionais se engajam na produção em regiões menos desenvolvidas? Skolnick \& Martin (1995).

Em síntese, ao longo dessa trajetória, de pouco mais de meio século, os processos decisórios relativos à $\mathrm{C} \& \mathrm{~T}$ tornaram-se mais abertos e passaram a incluir, além do mérito científico, os critérios do mérito tecnológico e do mérito social. Foi, porém, o período no qual se consolidou a importância do mérito tecnológico. Este critério foi valorizado ao se comprovar que, sob a ótica exclusiva do mérito científico, a relevância tecnológica de certas pesquisas não era percebida, tal como ocorreu com a biologia molecular, subestimada inicialmente, na Europa, pelos geneticistas clássicos e com as ciências da informação, descartadas enquanto pesquisa fundamental pelos matemáticos e físicos.

Na década dos 90, nos Estados Unidos, com o crescimento das restrições no financiamento público, aumentaram as pressões sociais sobre a ciência básica. É surpreendente ver que naquele país, onde o Estado destina para a pesquisa básica entre 10 a 20\% dos recursos públicos totais para C\&T, os cientistas necessitam aprimorar seu poder de lobby para exigir mais e mais recursos para a ciência fundamental, principalmente na área biomédica. Com efeito, os orçamentos destinados para as atividades científicas nos países desenvolvidos, sobretudo nos Estados Unidos, alcançaram tal volume que, até muito recentemente, apenas o tamanho da economia parecia ser o fator capaz de determinar o seu limite. Esta situação, de custos em espiral - principalmente os da pesquisa biomédica - gera pressões sobre a capacidade de financiamento dos estados, suscitando discussões políticas em torno dos patamares do investimento público na ciência básica.

Internacionalmente, os cientistas cada vez mais reconhecem que não será possível assegurar o crescimento em espiral do financiamento público às atividades de C\&T. Dedicam boa parte de seu tempo à tarefa de convencimento contínuo - da sociedade e dos políticos - de que a ciência básica também é imprescindível para a satisfação de necessidades so- 
ciais bem definidas. Nas páginas das mais conceituadas revistas científicas internacionais, com freqüência encontramos os star scientists - sobretudo os biocientistas mais produtivos argumentando que a pesquisa básica, além de responder pelo novo paradigma tecnológico, também contribui para a cultura, para o bem estar social, para a saúde pública e participa da geração da riqueza e da defesa nacional. São afirmações emanadas de uma elite intelectual que ainda preserva uma imagem bastante idealizada das atividades científicas.

O fato é que, não apenas nos Estados Unidos mas em diversos países - inclusive no Brasil - a aplicação do mérito social na avaliação da C\&T tem operado mais na defesa de interesses específicos dos cientistas do que como critério de escolha de prioridades sociais para o financiamento público. É inegável, porém, que atualmente, ao menos no plano internacional, existe uma tendência ao reconhecimento de que a pesquisa financiada com recursos públicos tem por obrigação originar contribuições imediatas e substantivas não apenas para a riqueza nacional, como para a qualidade de vida e o ambiente. Sem significar uma revalorização do tema "C\&T e desenvolvimento”, sem dúvida, ao final do século, difunde-se a visão favorável à maior contribuição da ciência à satisfação das necessidades sociais, como as de saúde e ao aprimoramento do provimento público de bem-estar, por meio da criação ou fortalecimento de diversos mecanismos de proteção social e ambiental.

\section{Sobre o conceito de sistema nacional de inovação}

A partir dos anos 50, um grupo de estudiosos se destacaria na análise econômica da mudança tecnológica, passando a ser conhecidos como os neo-schumpeterianos. Entre outros, alguns dos nomes mais representativos são Richard Nelson e Sidney Winter, da Universidade de Yale, Estados Unidos e que autodenominam sua abordagem de "evolucionista" e C. Freeman, C. Peres, K. Pavitt, L. Soete e G. Dosi, da Universidade de Sussex, UK Possas, (1989); Marques, 1991). Com base na noção central de Schumpeter de que a mudança técnica é a principal fonte de dinamismo nas economias capitalistas, a análise econômica da tecnologia avançaria muito mais do que a análise econômica da ciência.
Surgiram, desde os anos 60-70, muitos estudos empíricos e teóricos das fontes de inovação tecnológica e de suas conexões com o aumento da produtividade e com o poder econômico nacional. Amplamente, passou-se a afirmar que para um país ganhar a batalha da competitividade, era necessário introduzir uma dinâmica sistêmica dedicada à inovação tecnológica. Para alcançá-la não bastava dispor de um número suficiente de universidades e de grupos de excelência acadêmica, também não sendo suficiente aumentar o número de doutores e até mesmo elevar o volume dos recursos para a pesquisa. A definição de estratégias, planos e programas de desenvolvimento científico e tecnológico passou a ser uma prioridade para o Estado. Ganhou destaque o debate do planejamento da C\&T, não como um problema setorial, mas abarcando o conjunto de setores e também articulado com os diversos níveis do planejamento e localizado nas mais altas esferas do planejamento estratégico Martínez (1993). Para tanto, era necessário formular uma política de C\&T horizontal, isto é, articulada a outras políticas públicas, abrangendo a educação, a saúde, a indústria, a agricultura, o comércio, as relações exteriores, o sistema financeiro, a infra-estrutura, o emprego, entre outras.

A idéia de sistema nacional de inovação tornar-se-ia um elemento central nessas abordagens. Na interpretação de Freeman (1987), o sistema engloba agentes dos setores público e privado que interagem (networking), graças ao que iniciam, importam, modificam e difundem novas tecnologias. A idéia central é, portanto, a de uma malha ou rede de interações entre os componentes do sistema que visa a produção, a difusão e o uso de novos conhecimentos que sejam economicamente úteis. Essa visão sistêmica, não sendo considerada um novo marco conceitual, serve como uma referência para uma abordagem abrangente, englobando instituições, organizações e indivíduos.

Não é fácil, entretanto, estabelecer os limites internos de um sistema nacional de inovação. Para alguns, o sistema compreende um conjunto delimitado de instituições e organizações de C\&T. Outros adotam uma interpretação mais abrangente, englobando agentes produtivos, agentes financeiros e outros elementos que sejam relevantes. Outra dificuldade diz respeito à validade da fronteira geográfica para delimitá-lo, considerando que a 
globalização dos mercados financeiros e as crescentes facilidades de intercâmbio de informações científicas digitalizadas o caracterizam como um sistema aberto.

As instituições compreendem o vasto conjunto que vai das leis e normas regulamentares às práticas estabelecidas, ou seja, os hábitos, costumes e rotinas que pautam o comportamento das organizações e indivíduos no sistema. A função primordial dessas instituições é reduzir a incerteza, regular a interação e prover incentivos. O regime das patentes ou da proteção à propriedade intelectual é uma instituição regulatória decisiva no sistema.

As organizações são as estruturas formais executoras de diversas atividades relevantes: pesquisa básica e aplicada; disseminação do conhecimento; desenho, pesquisa, experimentação e desenvolvimento de produtos e processos; comercialização de novos produtos. São organizações do sistema: universidades; laboratórios de pesquisa das indústrias e do governo; provedores de informação; agências regulatórias; empresas públicas e privadas.

Trata-se de um mosaico de organizações que interagem e estabelecem vínculos, cada uma aportando conhecimento e competência específicos em busca de um desempenho inovador. Universidades fornecem teoria científica e princípios de engenharia; laboratórios fornecem especificações aos produtos, componentes e materiais; empresas fornecem conhecimentos sobre interação de componentes; usuários fornecem informação sobre oportunidades tecnológicas emergentes e performance dos produtos.

Direcionada para esse mosaico, a política de C\&T explícita deve contemplar o financiamento de certos alvos tecnológicos, o recurso ao poder de compra, as importações e as exportações e, entre outras medidas, o estimulo à criação de redes de informação e comunicação, a expansão e a modernização de institutos de pesquisa, de laboratórios e centros de pesquisa universitários, a formação e o treinamento de recursos humanos, a definição de temas de pesquisas prioritários e a adequação das normas e instrumentos legais referentes à compra, contratação, transferência, incorporação e utilização de tecnologia.

A ação governamental, ou melhor, a política pública, é, portanto, um componente essencial da noção de sistema nacional de inovação: estabelece prioridades, fornece incentivos diversos e, principalmente, financia a pes- quisa básica, em geral feita nas universidades, e que não é assumida pelo mercado por ser considerada de alto risco.

A interação entre os diversos componentes de um sistema nacional de inovação compreende também os relacionamentos profissionais e institucionais e a constante criação, durante o processo de inovação, de conhecimento tácito, isto é, da troca de informação não codificada - tão importante quanto a informação codificada - que resulta da experiência e da discussão no cotidiano sobre o funcionamento, na prática, das técnicas, métodos, desenhos e processos.

Verifica-se que os investimentos em informação, destinados ao incremento do estoque de conhecimentos, ditos investimentos intangíveis, são centrais na dinâmica do sistema. Incluem os investimentos públicos em ciência (pesquisa básica e formação de recursos humanos) e os investimentos privados em tecnologia, tais como gastos das empresas com P\&D, com patentes e com licenciamentos, bem como com os investimentos em educação e treinamento e em técnicas de gerência.

As diversas interpretações econômicas sugerem que regiões ricas nos "recursos do conhecimento", tais como universidades, escolas técnicas e uma boa infra-estrutura de informação, estão em vantagem comparativa para desenvolver atividades de $\mathrm{P} \& \mathrm{D}$. Tais recursos não são "naturais", mas são criados através de intervenções de Estado, de políticas públicas, explícitas e implícitas, implementadas durante um longo período de tempo, com claras implicações para o desenvolvimento - nacional, regional e local Luger (1994).

Uma interpretação limitada da noção de sistema nacional de inovação tecnológica, restrita à $P \& D$ e à educação técnica, passou a orientar, nos anos 60-70, a maior parte do trabalho relativo à C\&T da Organização Econômica para a Cooperação e o Desenvolvimento (OECD). Através da Organização dos Estados Americanos (OEA) essa concepção influenciaria o planejamento da C\&T e a discussão da inovação tecnológica na América Latina.

\section{Sobre o planejamento da C\&T na América Latina}

Durante os anos 70 e 80 muito se debateu e escreveu sobre ciência, tecnologia e desenvolvimento na América Latina, com as elites inte- 
lectuais abandonando definitivamente a concepção dominante no pós II Guerra Mundial da relação causal simples e linear entre aqueles três elementos e passando a beber na fonte do esforço analítico latino-americano que, desde a década dos 50 , fora dedicado ao problema do desenvolvimento e à compreensão das causas estruturais do "atraso" e da dependência tecnológica.

Tornou-se claro que não era possível avançar na análise do desenvolvimento tecnológico sem adentrar simultaneamente na crítica aos modelos de desenvolvimento das conjunturas passadas. Em especial, os milagres econômicos latino-americanos como os do Brasil, México e Argentina, haviam sido processos estreitamente dependentes dos investimentos estrangeiros, os quais, apesar de terem possibilitado intensa transferência de tecnologias sob a forma de equipamentos, não haviam transferido o processo de produção dessas tecnologias. Em meio à necessidade de articular as bases de uma estratégia, inicialmente, para a "independência nacional" e, posteriormente, alternativa ao esgotado modelo da substituição de importações, passou-se a conferir grande destaque à distinção entre políticas explícitas e implícitas de C\&T.

Progressivamente, foi ganhando ênfase a análise das relações entre tecnologia e estrutura produtiva, entre tecnologia e política econômica, entre tecnologia e ciência Guimarães et al., (1985). Cassiolato et al. (1983), analisando no início dos anos 80 a experiência e as perspectivas da política brasileira de C\&T, afirmavam que na década de 70 houve o maior crescimento nos investimentos em C\&T realizados pelo Brasil, em um esforço sem paralelo no resto da América Latina. De fato, o I Plano Nacional de Desenvolvimento para 19721974 já propunha a criação de um Sistema Nacional de Desenvolvimento Científico e Tecnológico e que veio a ser efetivamente constituído, incluindo entre outras instituições, o $\mathrm{CNPq}$, a Capes e a Finep e os institutos de pesquisa das empresas estatais. O país não chegou a apresentar, entretanto, nenhum resultado palpável na integração da política de C\&T ao desenvolvimento, pois faltou articular tal política com as demais políticas de desenvolvimento econômico e com outras políticas setoriais. Assim, as políticas de desenvolvimento postas em prática pela ditadura militar não consideraram a política brasileira de C\&T dos anos 70 como essencial.
O processo de ajuste estrutural iniciado com a crise da dívida externa de 1980-1982 traria os conhecidos efeitos devastadores sobre os países da América Latina, agravandose a distribuição desigual dos frutos do progresso técnico e os custos sociais. No cenário internacional, a progressiva "flexibilização" da produção industrial foi acompanhada pela crise dos mercados de trabalho e pelo agravamento do desemprego e na América Latina sobreveio a queda política e a quebra financeira do Estado desenvolvimentista Tavares (1993). Nesse processo, as políticas de C\&T foram sendo paulatinamente abandonadas.

Apesar da considerável expansão que os sistemas de inovação tecnológica na América Latina e Caribe tiveram durante os anos 70, ao final da década dos 90 encontram-se bastante enfraquecidos. As análises recentes disponíveis revelam que nenhum país da região conseguiu consolidar um sistema de inovação tecnológica efetivo de promoção da inovação tecnológica e de "saltos" para novos patamares de produtividade e competitividade Cardoza \& Villegas (1996) Alcorta \& Peres, 1998). Em síntese, ainda que se observe um certo nível de consolidação da $C \& T$ na região, a maior parte das atividades de pesquisa realizadas na América Latina não guarda relações com os setores produtivos.

No Brasil, nos anos 80, a Nova República retomou o debate sobre a política de C\&T, com a criação do Ministério da Ciência e Tecnologia e a sua controvertida política de informática. No início dos anos 90 o tema foi retomado implicitamente na política industrial do governo Collor. Nas duas últimas décadas, entretanto, o maior avanço continua sendo creditado à Assembléia Nacional Constituinte de 87-88, graças à qual a $\mathrm{C} \& \mathrm{~T}$, pela primeira vez, ao menos passou a fazer parte da Constituição Brasileira. Sobre o período mais recente, as informações empíricas conhecidas são controvertidas e as poucas análises disponíveis não são otimistas Fernandes et al. (1994). De modo geral, reconhece-se que a C\&T brasileira persiste isolada das estruturas produtivas, com as universidades absorvendo a maior parte dos recursos financeiros que continuam sendo predominantemente públicos. 


\section{Conclusão}

Nossa intenção aqui não foi pregar o simples abandono das políticas de Estado para a C\&T em face da sua atual orientação primordial para a consolidação de empresas e estruturas industriais competitivas. Reconhecendo as dificuldades e as novas possibilidades da ação do Estado na globalização dos mercados financeiros, reafirmamos a importância da retomada do tema do desenvolvimento para a definição de uma política nacional de C\&T exeqüível e de médio e longo prazo. Pensamos que somente terá legitimidade uma política de C\&T inserida em um projeto mais geral de desenvolvimento para o Brasil. O desafio do desenvolvimento, porém, não deve ser relegado exclusivamente às forças do mercado, pois as empresas, ainda quando amparadas por diversas medidas de Estado não se direcionam e não se propõem, por si só, a carrear a satisfação de todas as necessidades sociais e, muito menos, a resolver os problemas da devastação ambiental e da sobrevivência das futuras gerações.

Há dez anos, exaltávamos a importância da ação do Estado para alavancar o desenvolvimento da C\&T no Brasil, resultando em políticas públicas devidamente articuladas e tendo na devida conta a complexidade da sociedade brasileira Marques (1989). Hoje é possível acrescentar que essa reflexão sobre a ação do Estado em C\&T também deve contemplar a ampliação da noção de função pública, tendo em vista a proteção social e ambiental. É preciso ir além do cliché da necessidade de construção de um Estado de Bem-Estar como mero contrapeso às injustiças sociais decorrentes da lógica perversa do mercado. A acelerada desterritorialização da cultura, sobretudo do consumo cultural cotidiano, observada nos últimos dez anos e propiciada pela globalização, tornou necessária uma nova compreensão da função pública ancorada na recolocação do tema das responsabilidades cívicas Canclini (1997).

Consolida-se a consciência de que as tendências atuais referentes à condição humana, ou seja, ao consumo, não poderão prosseguir indefinidamente, tornando-se urgente a definição de uma sociedade viável ou da Welfare Society Vianna (1998). No plano epistemológico, esta retomada tem partido do reconhecimento de que a crença no poder do progresso científico para resolver todos os problemas humanos e ambientais da qual derivam racio- cínios lineares, deterministas, deverá ser sucedida pelo pensamento complexo Tarride (1998). Argumentamos que essas novas abordagens explicitam expectativas genéricas de uma nova ética para a C\&T que torne compatíveis o humanismo e a competitividade

Com o final da II Guerra Mundial, a expressão Welfare State veio a ganhar um novo significado, passando a exprimir a visão de um mundo novo emergindo dos destroços da guerra, apoiado na valorização da função pública na compatibilização entre democracia e economia de mercado Vianna (1998). Ou seja, já se fazia presente a expectativa de uma nova ética, para viabilizar o convívio de um novo humanismo com o imperativo da competitividade. É hora de recomeçar, conforme acabamos de verificar, após transitar por algumas das questões de base que emergem da experiência das políticas de C\&T dos últimos cinqüenta anos.

Sem dúvida, alcançada a virada do milênio, o tema ciência, tecnologia e desenvolvimento, continua suscitando muitas indagações novas e ainda carrega consigo, sem resposta, muitas questões antigas. Tendo estado em permanente revisão na segunda metade deste século, ganhou vitalidade, nas duas últimas décadas, com o crescimento mundial da conscientização das conseqüências das atividades humanas sobre o meio-ambiente. Ainda que no mundo globalizado, os motivos militares continuem emulando o debate das políticas de C\&T, a questão ecológica, além de não ser um modismo passageiro, no Brasil e internacionalmente, oferece novas possibilidades para a revisão da C\&T. O fôlego revelado pelo debate do desenvolvimento sustentável ao longo das décadas de 80 e 90, comprova a persistência da vontade coletiva - ao menos de parte da humanidade - de repensar o conceito.

Acreditamos que no futuro, a discussão dos rumos das políticas e das legislações nacionais de C\&T deverá ocupar posição cada vez mais central neste repensar do desenvolvimento, simultaneamente ao crescimento, nas esferas da negociação internacional, da regulação pactuada da C\&T, homogeneizando controvérsias de biossegurança, bioética e biodiversidade. Muitas dessas controvérsias nada mais são do que expressões concretas das dificuldades de compatibilizar interesses públicos e privados, humanismo e competitividade. 


\section{Referências}

Academia Brasileira de Ciências 1994. Encontros Setoriais: Contribuições de Ciência e Tecnologia para a Área Social de Saúde. Rio de Janeiro, 8 a 10 de junho (mimeo).

Alcorta L, Peres W 1998. Innovation systems and technological specialization in Latin America and the Caribbean. Research Policy 26: 857-881.

Brasil, Ministério da Saúde 1994. Anais da I Conferência Nacional de Ciência e Tecnologia em Saúde. Coordenação Geral de Desenvolvimento Científico e Tecnológico, Brasília, 476 pp.

Canclini NG 1997. Consumidores e Cidadãos. Conflitos Multiculturais da Globalização. UFRJ, Rio de Janeiro, 268 pp.

Cardoza G, Villegas R 1996. America Latina, p. 45-62. In World Science Report 1996, Unesco Publishing, Paris.

Cassiolato JE, Amaral Filho JB de S, Brunetti JLA, Souza Paula MC 1983. Experiência e perspectivas da política brasileira de ciência e tecnologia, p. 29-46. In Ciência, Tecnologia e Desenvolvimento 2. CNPq/ Unesco, Coleção de Estudos de Política Científica e Tecnológica, Brasília.

Collins FS et al. 1998. New goals for the U.S. Human Genome Project: 1998-1993 Science 282(5389): 682689.

Cook-Deegan RM 1994. Origins of the Human Genome Project. Risk: health, safety \& environment. Human Genome Symposium 5(2): 97-117.

Dasgupta P, David PA 1994. Toward a new economics of science. Research Policy 23: 487-521.

Fernandes AM et al. 1994. Colapso da Ciência e Tecnologia no Brasil. Relume-Dumará, Rio de Janeiro, 152 pp.

Freeman C 1987. Technology Policy and Economic Performance. Lessons from Japan. Pinter Publishers, London and New York, 155 pp.

Geiger RL 1997. What happened after Sputnik? Shaping university research in the United States. Minerva 35(4): 349-367.

Godet M 1994. From Anticipation to Action. A Handbook of Strategic Prospective Unesco Publishing, Paris, 283 pp.

Guimarães ED, Araújo Jr JT de, Erber F 1985. A Política Científica e Tecnológica. Jorge Zahar, Rio de Janeiro, 93 pp.

Hobsbawm E 1995. Era dos Extremos: o Breve Século XX: 1914-1991. Tradução: Marcos Santarrita, Companhia das Letras, São Paulo, 598 pp.

Luger MI 1994. Science and technology in regional economic development: the role of policy in Europe, Japan and the United States. Technology in Society 16(1): 9-33
MacLean M, Anderson J, Martin BR 1998. Identifying research priorities in public sector funding agencies: mapping science outputs on to user needs. Technology Analysis and Strategic Management 10(2): 139- 155 .

Marques MB 1989. A Reforma Sanitária Brasileira e a Política Científica e Tecnológica Necessária. Série Política de Saúde No. 8. Fiocruz, Rio de Janeiro, 34 pp.

Marques MB 1991. Ciência, Tecnologia, Saúde e Desenvolvimento Sustentado. Série Política de Saúde No. 11. Fiocruz, Rio de Janeiro, 93 pp.

Marques MB 1993. Patenting Life. Foundations of the Brazil-United States Controversy. Série Política de Saúde No. 13. Fiocruz, Rio de Janeiro, 104 pp.

Marques MB 1998. Por uma Política de Ciência e Tecnologia em Saúde no Brasil. Série Política de Saúde No. 17. Fiocruz, Rio de Janeiro, 138 pp.

Martínez E 1993. Introducción, p. 7-18. In Estrategias, Planificación y Gestión de Ciencia y Tecnologia. Nueva Sociedad, Unesco, Caracas.

Novaes HMD 1996. Políticas científicas e tecnológicas para a saúde coletiva. Ciência e Saúde Coletiva 1(1): 39-54.

Papon P, Barré R 1996. Science and technology systems: a global overview, p. 8-22. In World Science Report 1996, Unesco Publishing, Paris.

Possas ML 1989. Em direção a um paradigma microdinâmico: a abordagem neo-shumpeteriana, p. 157-177. In EJ Amadeo - Ensaios sobre Economia Política Moderna: Teoria e História do Pensamento Econômico, Marco Zero, São Paulo.

Salomon JJ (s.d.). Critérios para uma política de ciência e tecnologia. De um paradigma a outro, p. 9098, lóquio/Ciências, Lisboa.

Tarride MI 1998. Saúde Pública. Uma Complexidade Anunciada. Fiocruz, Rio de Janeiro, 107 pp.

Skolnick B, Martin B 1995. SPRU - The science policy research unit. Science, Technology and Innovation 10(3): 27-30

Tavares MC 1993. Ajuste e reestruturação nos países centrais: a modernização conservadora, p. 21-73. In MC Tavares \& JL Fiori (eds.) - Desajuste Global e Modernização Conservadora. Paz e Terra, Rio de Janeiro.

Teixeira A 1994. O Ajuste Impossível. Um Estudo sobre a Desestruturação da Ordem Econômica Mundial e seu Impacto sobre o Brasil. UFRJ, Rio de Janeiro, 184 pp.

Vianna MLTW 1998. A Americanização (perversa) da Seguridade Social no Brasil. Estratégias de Bem-Estar e Políticas Públicas. Revan, Ucam, Iuperj, Rio de Janeiro, 272 pp. 